Research Article

\title{
Experimental Investigation on Seepage Stability of Filling Material of Karst Collapse Pillar in Mining Engineering
}

\author{
Bangyong Yu $\mathbb{D},{ }^{1}$ Zhanqing Chen $\mathbb{D D}^{2}$ and Jiangyu Wu $\mathbb{D}^{2,3}$ \\ ${ }^{1}$ Institute of Construction Engineering Technology, Changzhou Vocational Institute of Engineering, Changzhou 213164, \\ Jiangsu, China \\ ${ }^{2}$ State Key Laboratory for Geomechanics \& Deep Underground Engineering, China University of Mining \& Technology, \\ Xuzhou 221116, Jiangsu, China \\ ${ }^{3}$ GeoEnergy Research Centre, Faculty of Engineering, University of Nottingham, University Park, Nottingham NG7 2RD, UK
}

Correspondence should be addressed to Zhanqing Chen; czq_edu@126.com

Received 18 May 2018; Accepted 26 August 2018; Published 30 September 2018

Academic Editor: Hualei Zhang

Copyright ( 2018 Bangyong Yu et al. This is an open access article distributed under the Creative Commons Attribution License, which permits unrestricted use, distribution, and reproduction in any medium, provided the original work is properly cited.

In northern China, groundwater inrush of Karst collapse pillar (KCP) often affects the coal mining process. Current studies rarely consider the seepage stability of filling materials of KCP, especially through experimental investigations. This study is to quantify the impacts of variable initial porosity and cementing strength on the seepage properties of filling material. For this purpose, we designed and fabricated a test system. This system can offer high water pressure and abundant water flow rate. We tested three types of specimens which were cemented by clay, gypsum, and cement, respectively. The seepage properties were obtained under the initial porosity of $0.11,0.13,0.15$, and 0.17 , respectively. The change mechanism of seepage properties was measured through the comparison between mass loss and mass gain. The results showed the followings findings: (1) The permeability-time curves have two types: the first type is that permeability gradually increases up to the occurrence of seepage instability and the second type is that permeability gradually decreases and approaches to a stable value. No seepage instability is observed. (2) Initial porosity and cementing material significantly affect the water flow properties of filling material. In general, larger initial porosity has larger permeability. For clay as cementing material, seepage instability occurs soon and higher initial porosity has shorter time to reach seepage instability. For gypsum, seepage instability occurs after a period of time when initial porosity is large enough. For cement, the permeability decreases gradually and approaches to a stable value. The permeability-time curves have rapid decrease and slow decrease. (3) The permeability has a magnitude of $10^{-15}-10^{-13} \mathrm{~m}^{2}$ and varies with initial porosity and cementing materials. The permeability is the largest for clay cementing and is the smallest for cement cementing.

\section{Introduction}

Karst collapse pillar (KCP) is a kind of geological structures extensively distributed in the North China coalfields. It is caused by the karst subsidence in carbonate rock [1-3]. The KCP usually connects to a high-pressure aquifer with abundant supply of groundwater. It is usually functioned as a channel for groundwater inrush [4]. Groundwater inrush generally induces a great damage to coal mining engineering; thus, the seepage instability of KCP has attracted worldwide attentions $[5,6]$.

Many investigations on groundwater inrush of KCP have been conducted in recent years. For example, Yin et al. presented a thick wall canister model and obtained a criterion of water inrush of KCP [7]. Wu et al. constructed a GISANN coupling model to evaluate the vulnerability of KCP water inrush [8]. They also performed sensitivity analysis for their model. Zhu and Wei established a damage-based hydromechanical model, and simulated the mininginduced water inrush behaviors after considering the effect of faults and KCP in numerical simulation [9]. Bai et al. established the plug model to describe the water seepage flow behaviors in coal seam floor containing KCP [4]. Yao et al. built a fluid-solid coupling model for KCP based on seepage theory of porous media [10]. Different methods have been developed to investigate the water inrush behaviors. Xiang 
conducted numerical tests to simulate the groundwater inrush process of KCP [11]. Wu et al. used an artificial neural network to determine the weight coefficient of each factor that affects water inrush. The characteristics of water disasters in North China coalfields were summarized by analyzing the hydrogeological conditions of mining areas [12]. $\mathrm{Ma}$ et al. developed a numerical fast Lagrangian analysis of continua in three dimensions model to understand the mechanical state of a coal seam penetrated by a KCP during mining panel extraction [13]. Ma and Bai further presented a new parameter optimization scheme for nonlinear grey Bernoulli model by using a genetic algorithm [3]. In addition, Zhang et al. analyzed those factors that influence groundwater transmissibility of KCP and discussed the types of groundwater inrush channels [14]. Yang et al. introduced the structure characteristics of KCP and proposed that the penetrating joints surrounding KCP is an optimal channel of water inrush [15]. However, the studies of seepage properties of filling materials of KCP are not extensive in both theoretical and experimental aspects. So, we developed an experimental study on the filling material in KCP and analyzed its seepage properties in this paper.

The complete filling material specimens are difficult to obtain from KCP due to its weak strength. In this study, we prepared the tested specimens with broken filling material as the main material. Considering the limitation of time, it is difficult to restore the original cementation state in a short time with the broken filling material alone. In addition, taking into account the geological environment and geological structure, we added different cementing materials which are available (clay, gypsum, and cement) into tested specimens. We then quantified the influence of initial porosity and cementing material on the seepage properties of these rock specimens. This paper is organized as follows. In Section 2, a self-designed test system is firstly presented. This system can offer high water pressure and abundant water flow. The fabrication process of rock specimens and the testing procedure are also presented in Section 2. Section 3 gives the permeability calculation method based on Darcy's law. Section 4 presents the test results, and Section 5 presents the discussions in details. Finally, Section 6 draws the findings in this study and explores the implication of these findings.

\section{Experimental System and Procedure}

2.1. Testing System. MTS815.02 test system has too small volume of the pressure intensifier which cannot supply enough water flow $[16,17]$; thus, a test system is designed to provide high water pressure and abundant water flow. Figure 1 illustrates the components of this system and their design principle. This self-designed test system has mainly four parts: pore water pressure control apparatus, data acquisition apparatus, seepage apparatus, and press machine. The pore water pressure control apparatus is mainly composed of hydraulic pump station, double-acting hydraulic cylinder, water pump, and other components. Water and hydraulic oil are, respectively, used as the transmission medium at the two sides of the piston in double-acting hydraulic cylinder. In this way, water flow can be injected to the specimen, while hydraulic oil can be used to control the water pressure. The data acquisition apparatus is mainly composed of liquid flow meter (measurement precision $0.01 \mathrm{~L} / \mathrm{h}$ ), pressure transducer (measurement precision $0.01 \mathrm{MPa}$ ), paperless recorder, and computer. It can monitor the water pressure and record the water flow rate. The press machine is used to fix the seepage apparatus. For the seepage apparatus, the water inlet piston (1), connected with the double-acting hydraulic cylinder, is used to offer the water flow. The $\mathrm{O}$-shape rubber seal rings (2) are used to close the gaps. The upper porous plate (3) with small through-holes (diameter $2 \mathrm{~mm}$ ) is used to ensure even water flows. The sealing material (4) is used to ensure that the water does not flow through the edge of the rock specimen. The rock specimen (5) is sealed in the center of the cylinder tube (7), of which the inner diameter and wall thickness are 100 and $21 \mathrm{~mm}$, respectively. The lower porous plate (6), with large through-holes (diameter $10 \mathrm{~mm}$ ), is used to ensure the smooth flow of water and fine particles.

2.2. Specimen Preparation. The filling material in KCP used in the test was taken from the Sima coal mine in Shanxi province of China. The specimens were prepared in laboratory according to the following procedure. The filling materials were firstly crushed, and the particles were separated into groups with diameter sizes ranging from 0 to 2.5 , 2.5 to 5,5 to 8,8 to 10,10 to 12 , and 12 to $15 \mathrm{~mm}$ using sieves. Considering that the filling material of KCP contains rock particles in different sizes, the particle groups in each specimen are constituted by grains diameter of a group (2.5-5 mm), b group (5-8 mm), c group ( $8-10 \mathrm{~mm})$, d group $(10-12 \mathrm{~mm})$, and e group $(12-15 \mathrm{~mm})$, and the total mass is $1000 \mathrm{~g}$. In order to overcome the dimension disaster and reduce the number of tested specimens, the particles within five sizes ranges are mixed according to Talbot theory [18]. The Talbot formula is

$$
P=\left(\frac{d}{D}\right)^{n} \times 100 \%
$$

where $P$ denotes the passing rate of each grain size in rock particles, $d$ is the grain diameter, $D$ is the maximum diameter, and $n$ is the Talbot exponent. Table 1 shows the details of mass amount of particles in each grain size range of each specimen (Talbot exponent $n=0.6$ ).

A preparation device as shown in Figure 2 was used to cast filling material specimens. The device is mainly composed of a pressing piston, cylinder, felt, pedestal, and other components. This cylinder has the inner diameter of $100 \mathrm{~mm}$ and the wall thickness of $10 \mathrm{~mm}$. Fully quenched $45 \#$ steel is used to improve the strength of the cylinder and to prevent the internal wall of cylinder from being scraped by sharp edges of rock particles.

This test selected clay, gypsum and cement as cementing materials to simulate different geological structures. Considering the geological environment and geological structure, for each cementing material, the initial porosity was taken as $0.11,0.13,0.15$, and 0.17 , respectively. The fabrication of the 


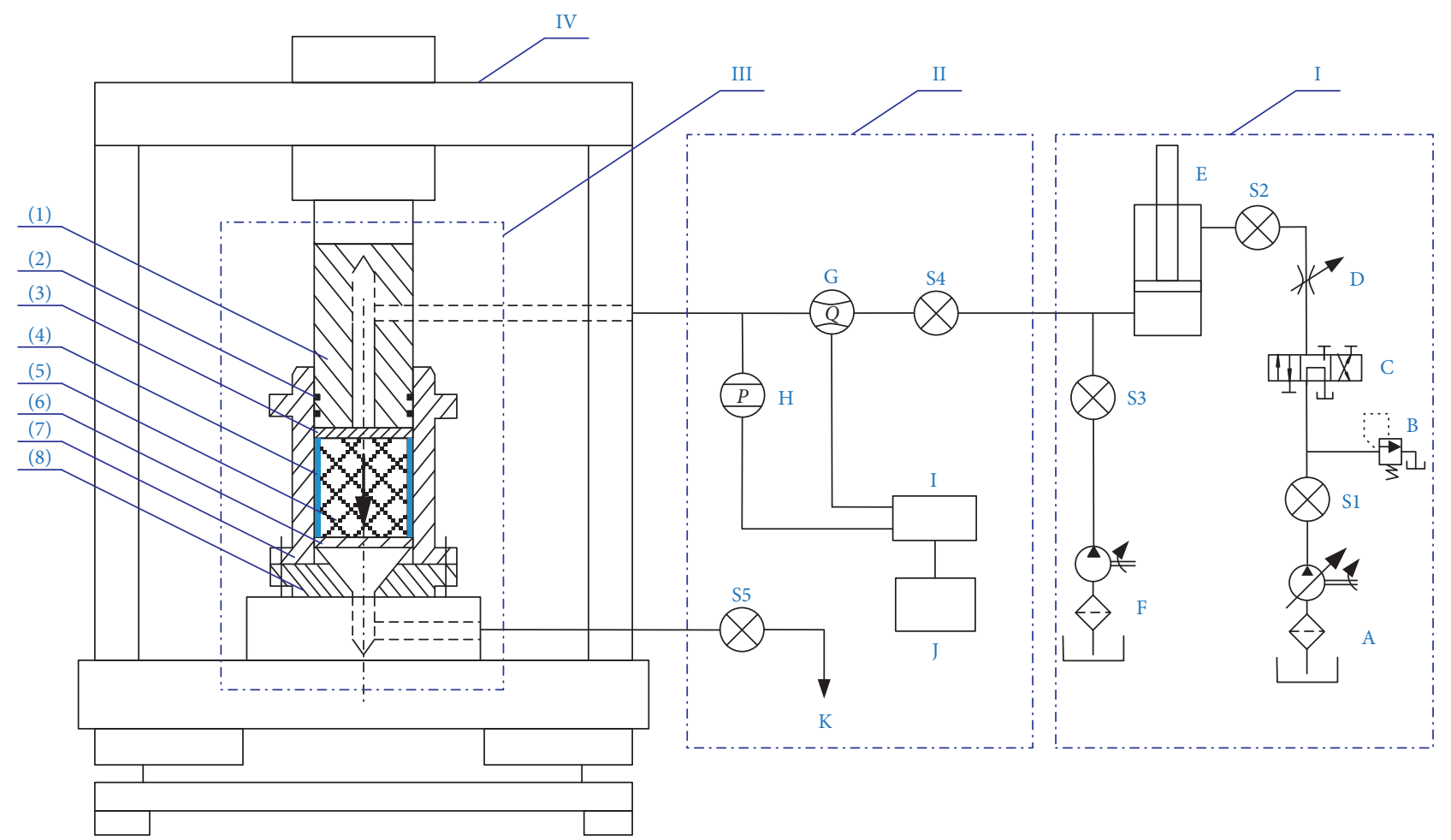

FIGURE 1: Test system. I-pore water pressure control apparatus, II-data acquisition apparatus, III-seepage apparatus, IV press machine (MTS816.03), S1-S5 switches, A-hydraulic pump station, B-pressure relief valve, C-reversing valve, D-one-way valve, E-double-acting hydraulic cylinder, F-water pump, G-fluid flow meter, H-pressure transducer, I-paperless recorder, J-computer; K-water outlet. (1) Water inlet piston, (2) O-shape rubber seal ring, (3) upper porous plate, (4) sealing material, (5) rock specimen, (6) lower porous plate, (7) cylinder tube, and (8) based pedestal.

TABLE 1: The details of mass amount of filling material particles in each grain size range to each specimen (Talbot exponent $n=0.6$ ).

\begin{tabular}{lllllll}
\hline Grain size range $(\mathrm{mm})$ & $0-2.5$ & $2.5-5$ & $5-8$ & $8-10$ & $10-12$ & $12-15$ \\
\hline
\end{tabular} \begin{tabular}{llllllll}
\hline Rock particle mass (g) & 341.3 & 176.0 & 168.5 & 98.3 & 90.6 & 125.3 \\
\hline
\end{tabular}

specimens observes the following procedure: first, take $1000 \mathrm{~g}$ of particles and mix them with $100 \mathrm{~g}$ of cementing material. It is noted that the mass of particles in each particle size range was calculated through Formula (1). Then, add $60 \mathrm{~g}$ of water and stir evenly. Pour the mixture into the pressing cylinder and use the press machine to apply an axial load to push the mixture to the preset height. Finally, keeping the height, take the specimen out after seven days. The prepared specimens are shown in Figure 3.

Initial porosity of the specimen is a measure of the fraction of void space in the specimen at the initial state and is defined by

$$
\varphi_{\mathrm{o}}=1-\frac{\left(m_{\mathrm{f}} / \rho_{\mathrm{f}}\right)+\left(m_{\mathrm{c}} / \rho_{\mathrm{c}}\right)}{Q_{\mathrm{s}} h},
$$

where $\varphi_{\mathrm{o}}$ is the initial porosity, $m_{\mathrm{f}}$ and $m_{\mathrm{c}}$ are the masses of filling material and cement material, and $\rho_{\mathrm{f}}$ and $\rho_{\mathrm{c}}$ are the density of filling material and cement material, $Q_{s}$ and $h$ are the section area and height of the specimen. Based on Equation (2), we can control the initial porosity by controlling the height of the specimens.

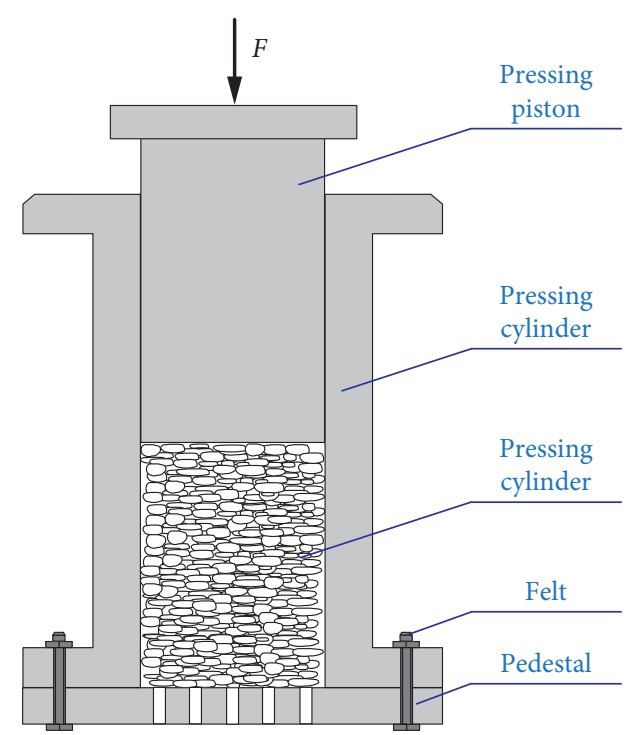

Figure 2: Preparation device for tested specimen.

2.3. Testing Procedure. The kinetic viscosity of water used in the test is $\mu_{0}=1.01 \times 10^{-3} \mathrm{~Pa} \cdot \mathrm{s}$ at the room temperature. The three groups of filling material specimens were tested one by one. The test steps are stated as follows.

2.3.1. Seal the Specimen. Sealing material (waterproof cement) is used to seal the dry specimen in the cylinder tube. 


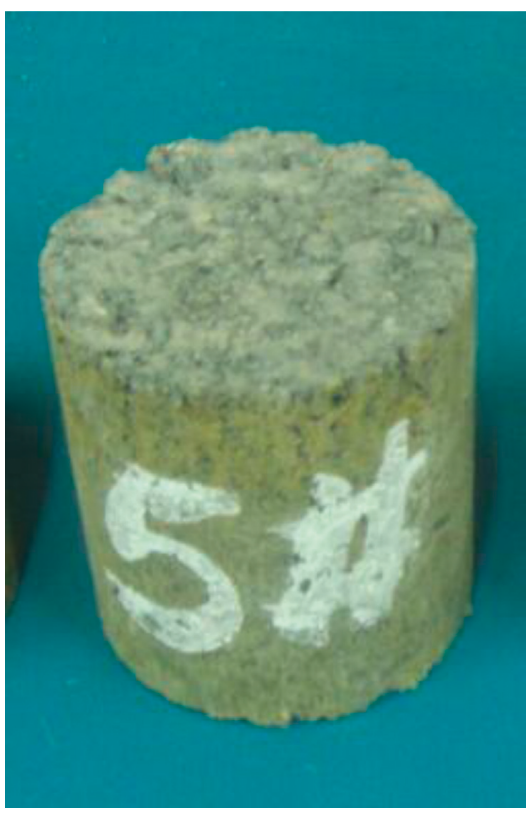

(a)

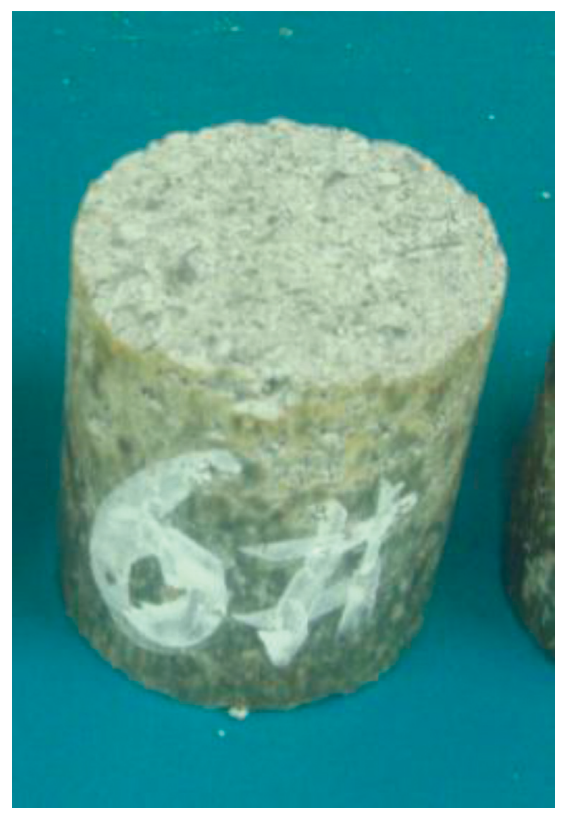

(b)

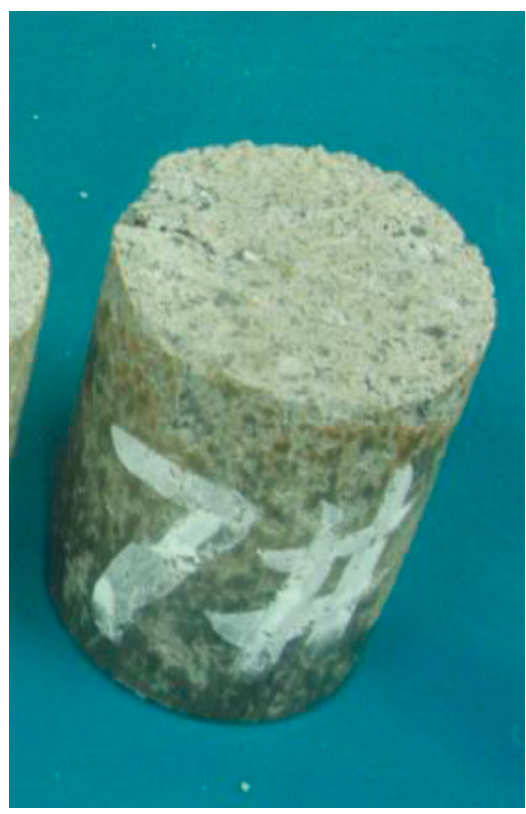

(c)

FIgURE 3: Rock specimens. (a) Specimen cemented by clay; (b) specimen cemented by gypsum; (c) specimen cemented by cement.

After the complete solidification of the waterproof cement, place the seepage apparatus on the platform of the compression machine.

2.3.2. Fix the Seepage Apparatus. Apply the axial load $(0.2 \mathrm{kN})$ to ensure the seepage apparatus fixed.

\subsubsection{Inject Water to the Double-Acting Hydraulic Cylinder.} Start the water pump to inject water into the double-acting hydraulic cylinder. When the piston reaches the peak, turn off the water pump.

2.3.4. Saturate the Specimen. Set the pore water pressure gradient at a small value (less than $1.0 \times 10^{-3} \mathrm{MPa} / \mathrm{mm}$ ), and then inject water flow to the specimen for 30 minutes to ensure the specimen saturated.

2.3.5. Set the Pore Water Pressure and Start the Seepage Test. Start the hydraulic pump station and then adjust the pressure relief valve for water pressure needed. Start the seepage test after the pore water pressure reaches the preset value.

In the test, the pore water pressure gradient is set to $4.0 \times 10^{-2} \mathrm{MPa} / \mathrm{mm}$. Figure 4 illustrates the entire experimental procedure.

\section{Permeability Calculation Based on Darcy's Law}

Darcy's law [19] can be used to model our investigation since it has proved to fit the water flow in rocks well [20]. For onedimensional Darcy flow, the relationship between pressure and flow velocity can be expressed as

$$
-\frac{\partial p}{\partial z}=\mu_{0} k^{-1} v,
$$

where $\partial p / \partial z$ is the pore water pressure gradient, $p$ is the pore water pressure, $z$ is the vertical axis going through the center of the specimen, $\mu_{0}$ is the kinetic viscosity of the water, $k$ is the permeability, $v$ is the water flow velocity. The water flow velocity $v$ can be calculated through the flow rate as

$$
v=\frac{4 Q}{\pi d_{\mathrm{s}}^{2}},
$$

where $Q$ is the water flow rate and $d_{\mathrm{s}}$ is the diameter of the tested specimen.

In the test, the upstream end of the rock specimen was connected to the double-acting hydraulic cylinder of the test system. Such a connection can control the pore water pressure through the pressure relief valve. $p_{1}$ is the pressure at the intake boundary. The downstream end of the rock specimen was connected to the atmosphere; thus, the pore water pressure $p_{2}$ equals zero.

If all the parameters on the right side of Equation (3) do not change with $z$, the pore water pressure gradient $\partial p / \partial z$ is a constant which can be calculated by

$$
\frac{\partial p}{\partial z}=\frac{\left(p_{2}-p_{1}\right)}{H}=-\frac{p_{1}}{H},
$$

where $H$ is the specimen height. Therefore, the pressure gradient at the intake can be calculated by Equation (3) as

$$
\frac{p_{1}}{H}=\mu_{0} k^{-1} v
$$

Thus, the permeability $k$ of the cemented broken rocks can be calculated if the water flow velocity $v$ is known. 


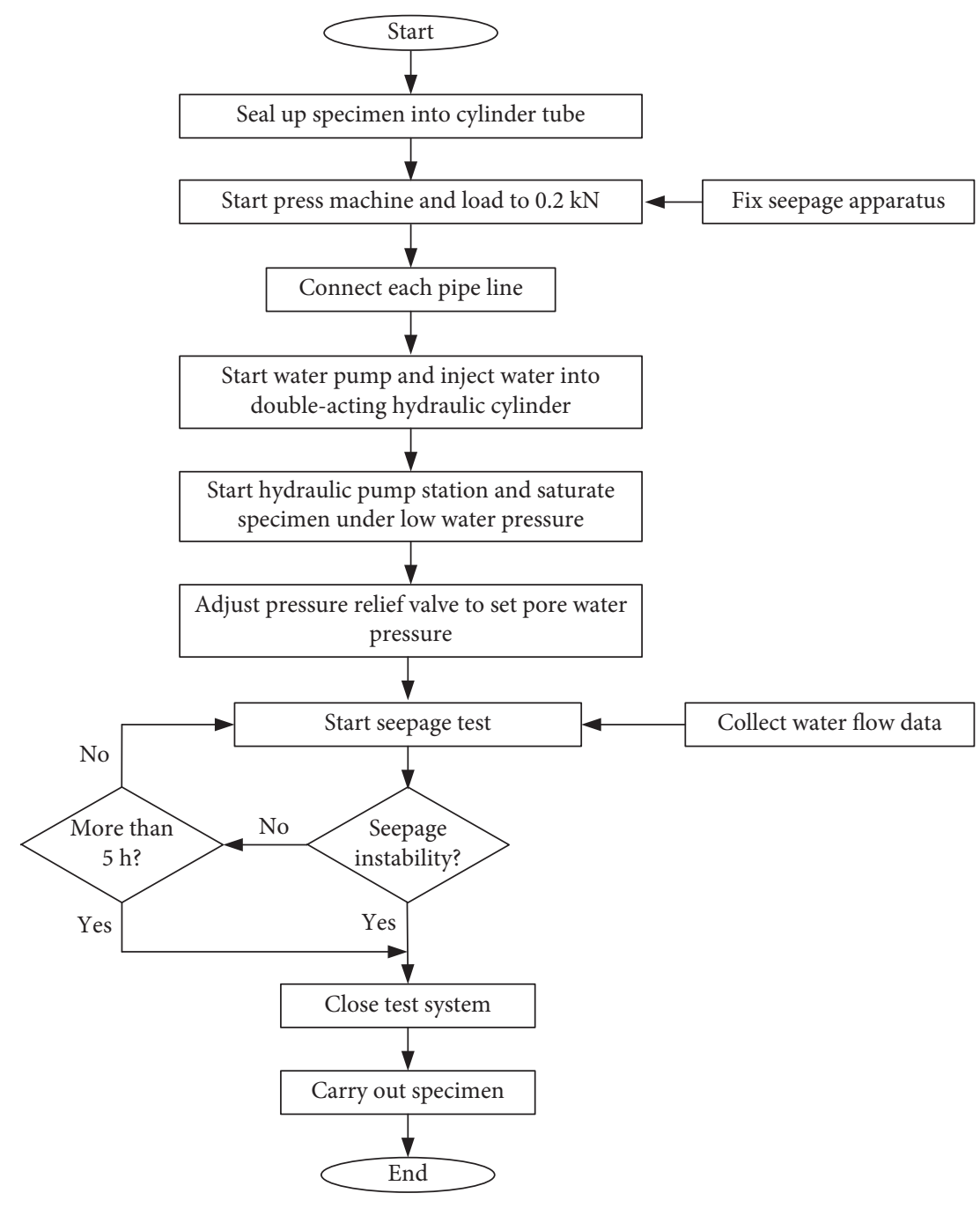

FIgURE 4: Testing procedure.

\section{Test Results}

The filling material specimens with various initial porosity and cementing materials are tested under the fixed pore water pressure gradient of $4.0 \times 10^{-2} \mathrm{MPa} / \mathrm{mm}$. The seepage property parameters are presented in Table 2 . When the seepage changes into pipe flow and water flow velocity increase sharply along with lots of particles flowing out of specimens, this change is called seepage instability, and the duration is seepage instability $T$. When the permeability gradually decreases and approaches to a stable value, this value is called stable permeability $k_{\mathrm{s}}$. Following evolutions can be revealed:

For the specimens cemented by clay, as shown in Figure 5, the permeability-time curves all gradually increase and display obvious fluctuations. Seepage instability occurs soon after about 30-300 seconds. Bigger initial porosity has more intense fluctuations and shorter time required to reach seepage instability. As shown in Figure 6, the relationship of seepage instability duration and initial porosity can be described by an exponential function, and the correlation coefficient is 0.9821 .

For the specimens cemented by gypsum, Figure 7 shows that the permeability-time curve has two types. The first type belongs to the specimens with very small initial porosity ( 0.11 or 0.13$)$. Their permeability gradually decreases and approaches to a stable value. The curves display weak fluctuations. The second type has large initial porosity $(0.15$ or 0.17 ). Their permeability gradually increases, and seepage instability occurs after a period of time, about 4000 seconds and 6000 seconds, respectively, in our tests. The curves display more intense fluctuations than that of specimens with small initial porosity.

For the rock specimens cemented by cement, Figure 8 shows that the permeability-time curves monotonously decrease without fluctuations, and the decrease process can be divided into two main stages: the rapid decrease and slow decrease.

As shown in Figure 9, it is found that the permeability has a magnitude of $10^{-15}-10^{-13} \mathrm{~m}^{2}$, while the permeability of specimens cemented by clay is larger than that of gypsum and cement. To each group of rock specimens with same cementing material, in general, larger initial porosity of the specimen corresponds to larger permeability. The relationship between initial permeability and initial porosity can be described by 
TABLE 2: The seepage property parameters.

\begin{tabular}{|c|c|c|c|c|}
\hline Specimen & Initial porosity & Initial permeability $k_{0}\left(10^{-14} \mathrm{~m}^{2}\right)$ & Stable permeability $k_{\mathrm{s}}\left(10^{-14} \mathrm{~m}^{2}\right)$ & Seepage instability duration $T(\mathrm{~s})$ \\
\hline \multirow{4}{*}{ With clay } & 0.11 & 2.83 & - & 278 \\
\hline & 0.13 & 4.64 & - & 180 \\
\hline & 0.15 & 7.80 & - & 77 \\
\hline & 0.17 & 14.38 & - & 34 \\
\hline \multirow{4}{*}{ With gypsum } & 0.11 & 1.85 & 0.49 & - \\
\hline & 0.13 & 3.10 & 1.09 & - \\
\hline & 0.15 & 3.69 & - & 5996 \\
\hline & 0.17 & 4.99 & - & 4003 \\
\hline \multirow{4}{*}{ With cement } & 0.11 & 1.70 & 0.13 & - \\
\hline & 0.13 & 2.18 & 0.29 & - \\
\hline & 0.15 & 2.65 & 0.44 & - \\
\hline & 0.17 & 4.89 & 1.11 & - \\
\hline
\end{tabular}

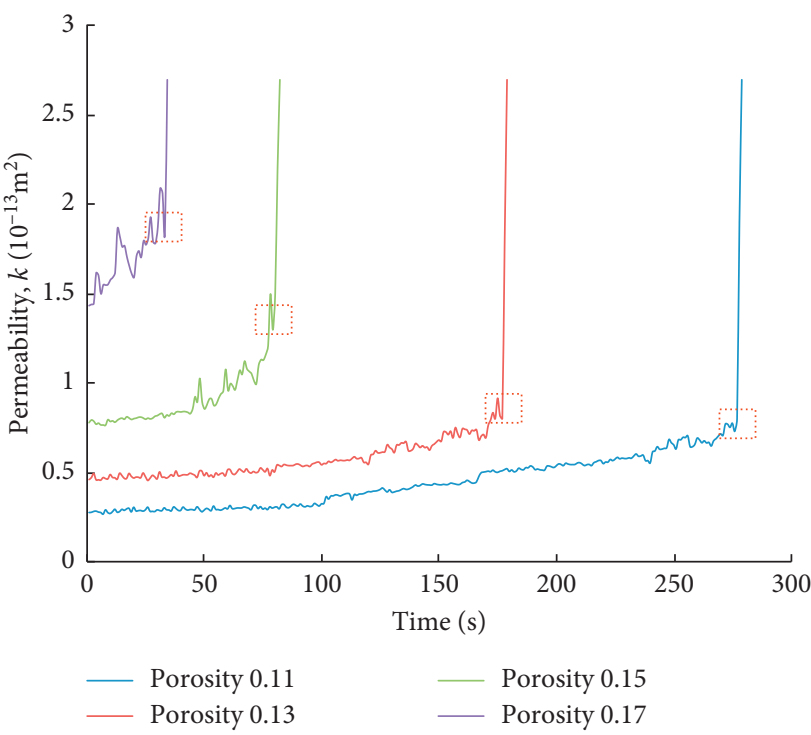

FIGURE 5: Permeability-time curves of tested specimens cemented by clay (the red rectangles mark seepage stability).

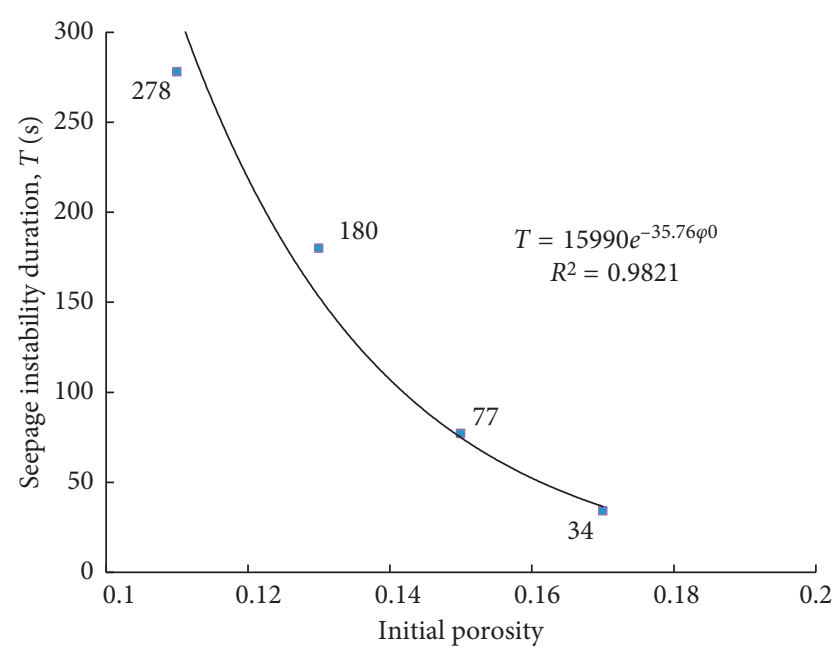

FIGURE 6: Relationship of seepage instability duration and initial porosity.

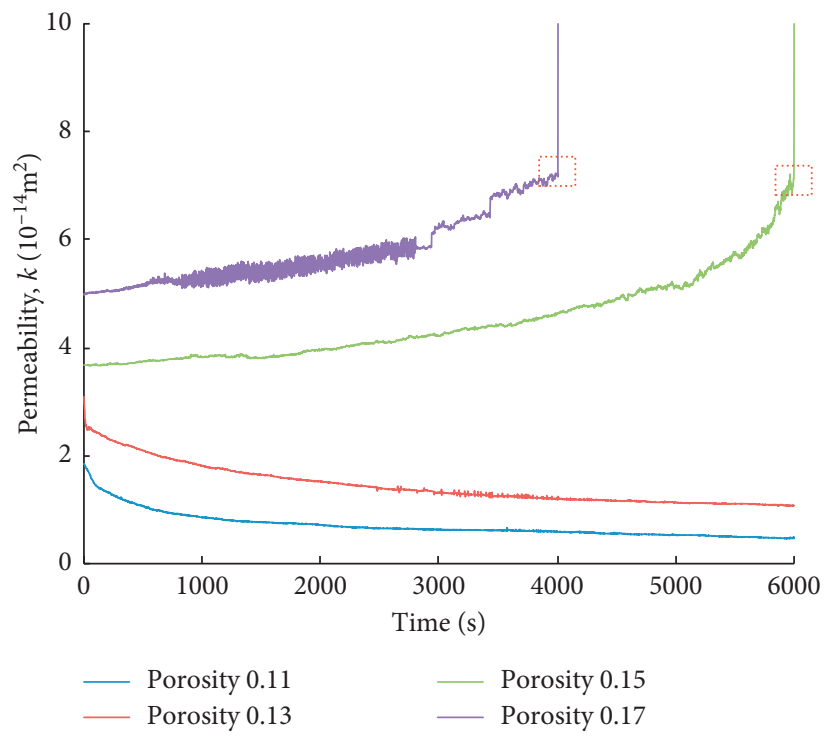

Figure 7: Permeability-time curves of tested specimens cemented by gypsum (the red rectangles mark seepage instability).

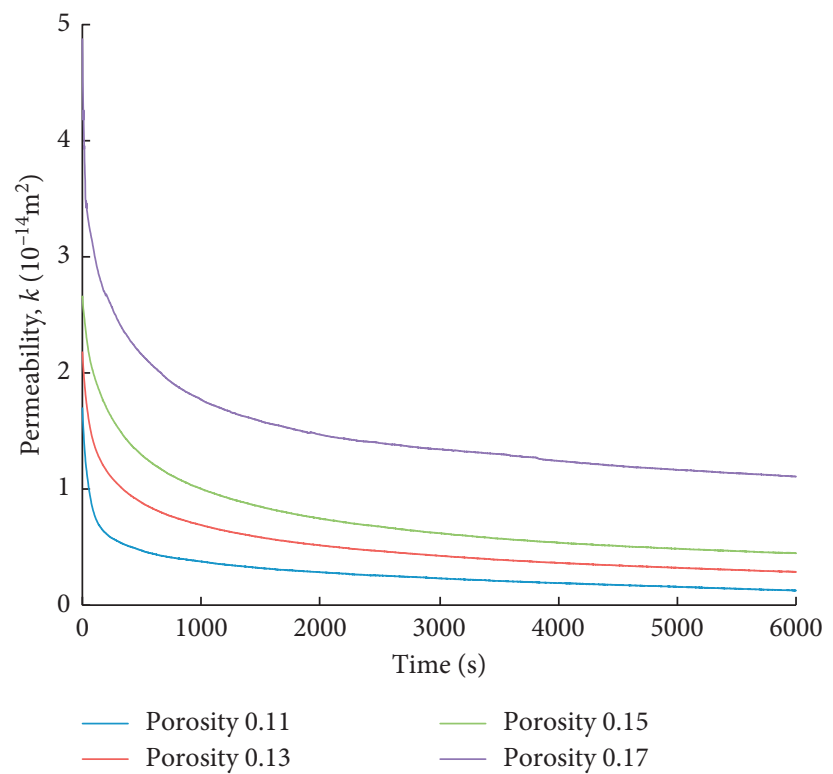

FIgURE 8: Permeability-time curves of rock specimens cemented by cement. 


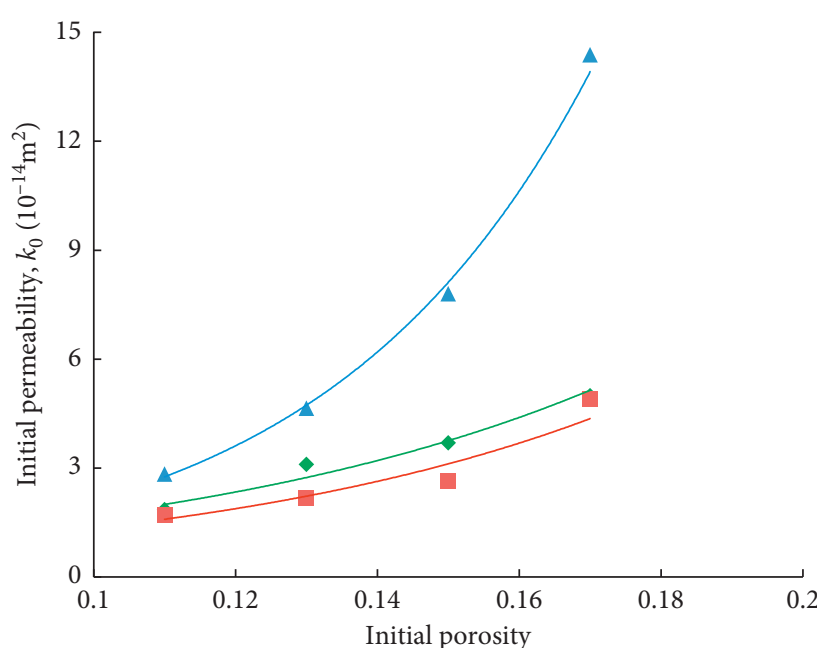

$\Delta$ With clay

- With gypsum

With cement

FIGURE 9: Initial permeability-initial porosity curves.

$$
k_{0}=a e^{b \varphi_{0}},
$$

where $k_{0}$ is the initial permeability, $\varphi_{0}$ is the initial porosity, $a$ and $b$ are the fitting coefficients, and the value is shown in Table 3 .

\section{Discussion}

Up to now, few literatures have been reported to study the groundwater inrush of KCP from the viewpoint of seepage instability of cemented filling material. Some results in the studies of seepage properties of broken (crushed) rocks have been achieved $[3,16,21]$. However, the broken rocks are granular material, of which physical and mechanical characteristics are far different from filling material in KCP.

In this test, with the corrosion and washout of water flow, partial fine particles will be washed away, which results in mass loss. Meanwhile, the hydration reaction, cementing materials combining with water, will result in mass gain. Both mass loss and mass gain will change the pore structure of specimens, so the cemented filling material is a kind of evolutive porous media. In the seepage process of cemented filling material, permeability depends on the porosity of the specimens [4]. Larger porosity corresponds to larger permeability. Therefore, we can analyze the change rule of the permeability through studying that of the porosity.

At the moment of $t$, for a microunit $\delta \Omega$ in the specimen, letting $\varphi$ be its porosity, the volume of the solid in the microunit is $\delta \Omega_{\mathrm{s}}=(1-\varphi) \delta \Omega$. The apparent density of microunit can be expressed by

$$
\rho_{\mathrm{s}}=(1-\varphi) m \text {, }
$$

where $m$ is the mass density of the solid in microunit, $\rho_{\mathrm{s}}$ is the apparent density of microunit. The mass of the solid in microunit, $\delta M_{\mathrm{s}}$, can be described as
TABLE 3: The fitting coefficients in the relationship between initial permeability and initial porosity.

\begin{tabular}{lccc}
\hline Specimen & $a$ & $b$ & Correlation coefficient \\
\hline With clay & 0.1418 & 26.98 & 0.9975 \\
With gypsum & 0.3532 & 15.76 & 0.9566 \\
With cement & 0.2497 & 16.83 & 0.9276 \\
\hline
\end{tabular}

$$
\delta M_{\mathrm{s}}=\rho_{\mathrm{s}} \delta \Omega=m \delta \Omega_{\mathrm{s}} .
$$

Let $q_{1}$ and $q_{\mathrm{g}}$ be the rates of the mass loss and mass gain, respectively, namely, mass loss and mass gain in unit volume per unit time, and then the mass increase of the solid in microunit after a little time $d t$ is $\left(q_{\mathrm{g}}-q_{\mathrm{l}}\right) \delta \Omega d t$. So we can obtain

$$
\delta M_{\mathrm{s}}^{\prime}=\left(\rho_{\mathrm{s}}+\frac{\partial \rho_{\mathrm{s}}}{\partial t} d t\right) \delta \Omega,
$$

where $\delta M_{s}^{\prime}$ is the mass of the solid in microunit at the moment of $t+d t$.

Based on the law of conservation of mass, for the solid in the microunit, the mass at the moment of $t+d t$ is the sum of the mass at the moment of $t$ and the mass increase during $d t$, and the relationship is as follows:

$$
\left(\rho_{\mathrm{s}}+\frac{\partial \rho_{\mathrm{s}}}{\partial t} d t\right) \delta \Omega=\rho_{\mathrm{s}} \delta \Omega+\left(q_{\mathrm{g}}-q_{\mathrm{l}}\right) \delta \Omega d t .
$$

Simplifying Equation (11), we have

$$
\frac{\partial \rho_{\mathrm{s}}}{\partial t}=q_{\mathrm{g}}-q_{1}
$$

Substituting Equation (8) in Equation (12), we can obtain

$$
\frac{\partial \varphi}{\partial t}=\frac{q_{1}-q_{\mathrm{g}}}{m}
$$

Equation (13) illustrates that the change rule of the porosity depends on the rate of mass loss $q_{1}$ and the rate of mass gain $q_{\mathrm{g}}$. If $q_{\mathrm{l}}>q_{\mathrm{g}}$, the porosity will increase, thus resulting in the increase of the permeability. After the mass loss reaches a certain extent, the overall structure of the specimen will be destroyed, and then the seepage instability occurs. If $q_{\mathrm{l}}<q_{\mathrm{g}}$, the porosity will decrease, resulting in the decrease of the permeability. If $q_{\mathrm{l}} \approx q_{\mathrm{g}}$, the porosity mainly keeps constant and the permeability tends to be stable.

For the specimens cemented by clay, the cohesion is reduced significantly after the specimen is corroded by water flow, and then partial fine particles are washed away. Without mass gain, the porosity gradually increases which results in the increase of permeability. Because of the adjustment of pore structure caused by mass loss, the permeability-time curves display obvious fluctuations. For the specimens with larger initial porosity, the permeabilitytime curves display more intense fluctuations and the time required to reach seepage instability is shorter, which imply that the rate of the mass loss $q_{1}$ in these specimens is larger.

For the specimens cemented by gypsum, the hydration reaction takes place and the chemical equation is as follows: 


$$
\mathrm{CaSO}_{4} \cdot \frac{1}{2} \mathrm{H}_{2} \mathrm{O}+\frac{3}{2} \mathrm{H}_{2} \mathrm{O} \longrightarrow \mathrm{CaSO}_{4} \cdot 2 \mathrm{H}_{2} \mathrm{O}
$$

Based on Equation (14), we can find that the molar mass of the resultant $\mathrm{CaSO}_{4} \cdot 2 \mathrm{H}_{2} \mathrm{O}$ is larger than that of $\mathrm{CaSO}_{4} \cdot(1 / 2) \mathrm{H}_{2} \mathrm{O}$, which implies the existence of mass gain in specimens. Meanwhile, partial fine particles are washed away and the resultant $\mathrm{CaSO}_{4} \cdot 2 \mathrm{H}_{2} \mathrm{O}$ is slightly soluble in water, both of them result in mass loss. For the specimens whose initial porosity is small ( 0.11 or 0.13$)$, the permeability gradually decreases, which illustrates that the porosity decreases and the rate of mass gain $q_{\mathrm{g}}$ is larger than that of the mass loss $q_{1}$. In contrast, for the specimens whose initial porosity is large $(0.15$ or 0.17$)$, the permeability gradually increases along with obvious fluctuations and the seepage instability occurs after a period of time, which illustrates that the porosity increases and the rate of mass loss $q_{1}$ is larger than that of the mass gain $q_{\mathrm{g}}$. Compared with the specimens cemented by clay, the seepage instability of the specimens cemented by gypsum shows an obvious delay; this is mainly because the cohesion of specimens cemented by gypsum is larger and the rate of mass decrease $\left(q_{\mathrm{l}}-q_{\mathrm{g}}\right)$ is lower.

For the specimens cemented by cement, the cement clinker used in this test mainly contains $3 \mathrm{CaO} \cdot \mathrm{SiO}_{2}$, $2 \mathrm{CaO} \cdot \mathrm{SiO}_{2}, \quad 3 \mathrm{CaO} \cdot \mathrm{Al}_{2} \mathrm{O}_{3}$, and $4 \mathrm{CaO} \cdot \mathrm{Al}_{2} \mathrm{O}_{3} \cdot \mathrm{Fe}_{2} \mathrm{O}_{3}$. During the seepage process, the hydration reaction of cement clinker takes place, and the chemical equations are as follows:

$$
\begin{aligned}
& 2\left(3 \mathrm{CaO} \cdot \mathrm{SiO}_{2}\right)+6 \mathrm{H}_{2} \mathrm{O} \longrightarrow 3 \mathrm{CaO} \cdot 2 \mathrm{SiO}_{4} \\
& \cdot 3 \mathrm{H}_{2} \mathrm{O}+3 \mathrm{Ca}(\mathrm{OH})_{2} \\
& 2\left(2 \mathrm{CaO} \cdot \mathrm{SiO}_{2}\right)+4 \mathrm{H}_{2} \mathrm{O} \longrightarrow 3 \mathrm{CaO} \cdot 2 \mathrm{SiO}_{4} \\
& \cdot 3 \mathrm{H}_{2} \mathrm{O}+\mathrm{Ca}(\mathrm{OH})_{2} \\
& 3 \mathrm{CaO} \cdot \mathrm{Al}_{2} \mathrm{O}_{3}+6 \mathrm{H}_{2} \mathrm{O} \longrightarrow 3 \mathrm{CaO} \\
& \cdot \mathrm{Al}_{2} \mathrm{O}_{3} \cdot 6 \mathrm{H}_{2} \mathrm{O} \\
& 4 \mathrm{CaO}_{2} \mathrm{Al}_{2} \mathrm{O}_{3} \cdot \mathrm{Fe}_{2} \mathrm{O}_{3}+7 \mathrm{H}_{2} \mathrm{O} \longrightarrow 3 \mathrm{CaO} \\
& \cdot \mathrm{Al}_{2} \mathrm{O}_{3} \cdot 6 \mathrm{H}_{2} \mathrm{O}+\mathrm{CaO} \cdot \mathrm{Fe}_{2} \mathrm{O}_{3} \cdot \mathrm{H}_{2} \mathrm{O}
\end{aligned}
$$

Based on Equation (15), we can find that the molar mass of the resultants is larger than that of cement clinker, which implies the existence of mass gain in specimens. Due to the large cementing strength of cement, particle loss hardly occurs. So, the porosity gradually decreases resulting in the monotonous decrease of permeability. In the early stages of the tests, the permeability decreases rapidly mainly because the concentration of the cement clinker is large, which results in the large rate of hydration reaction. In contrast, in the late stages, the concentration is very small, so the permeability decreases slowly and tends to be stable.

In this test, it is found that the water flow at the outlet contains fine particles, which indicates the existence of mass loss. In addition, an obvious water channel is formed, and lots of particles flow out of the specimen after seepage instability, as shown in Figures 10(a) and 10(b), respectively.

In mining engineering, mining activity disturbs the KCP. With the corrosion of underground water, both the strength and the cohesion of filling material are reduced, and the

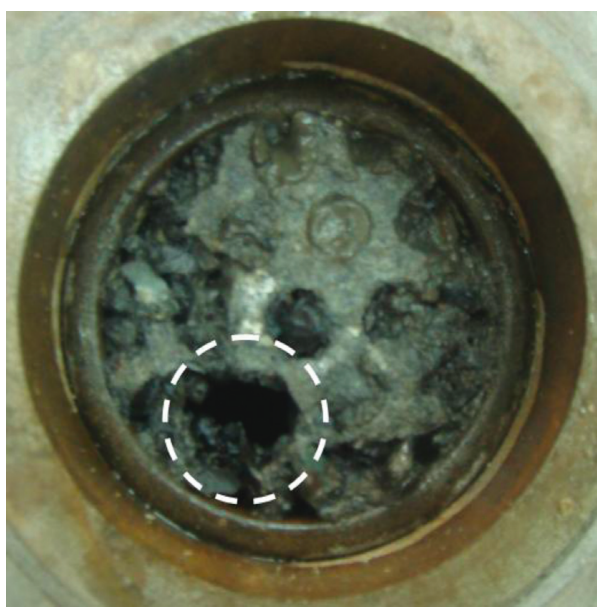

(a)

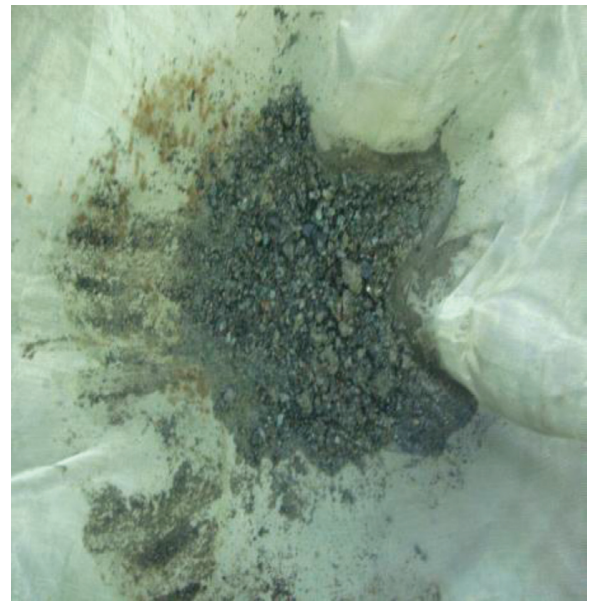

(b)

FIgURE 10: Specimen after seepage instability. (a) Water channel after seepage instability and (b) particles out of the specimen.

internal fine rock particles are washed away, and the pore structure evolves continuously. These may finally induce groundwater inrush. If the cementing strength of the cementing material is significantly weakened after it contacts water, the preventive actions should be taken before the disclosure of the KCP. If the strength of filling material is great but the internal mineral composition is soluble, the groundwater inrush may still take place after a period of time. The preventive actions should be taken after the KCP is disclosed. In addition, it was found that the permeability of the filling material cemented by cement is the minimum and no seepage instability occurs. Therefore, cement grouting is an effective method to prevent the water inrush of KCP.

\section{Conclusions}

In this paper, the impact of initial porosity and three cementing materials on permeability and seepage stability of cemented filling material was investigated by performing a series of laboratory tests with our self-designed test system. Through the above study, following conclusions can be drawn: 
(1) The permeability of the cemented filling material evolves over time, which has two types. The first one is that the permeability gradually increases and seepage instability occurs. The permeability-time curves display local fluctuations. Greater initial porosity has more intense fluctuations in the curves. The other type is that the permeability gradually decreases and tends to be stable. The permeabilitytime curves display weak local fluctuations.

(2) Water flow properties in KCP are strongly influenced by initial porosity and cementing material. In general, larger initial porosity of the specimen corresponds to larger permeability. If the cementing material is clay, the seepage instability occurs soon and higher initial porosity has shorter time to reach seepage instability. The relationship of seepage instability duration and initial porosity can be described by an exponential function. If the cementing material is gypsum, when the initial porosity is large enough, the seepage instability occurs after a period of time. If the cementing material is cement, the permeability of the specimen decreases gradually and tends to be stable, and the permeability-time curves can be divided to two stages: the rapid decrease and the slow decrease. The permeability of the filling material cemented by cement is the minimum, and no seepage instability occurs. Therefore, cement grouting is an effective method to prevent the water inrush of KCP.

(3) The permeability is observed in the magnitude of $10^{-15}-10^{-13} \mathrm{~m}^{2}$, while the permeability of specimens cemented by clay is larger than that of rock specimens cemented by gypsum and cement. The relationship between initial permeability and initial porosity can be described by an exponential function.

\section{Data Availability}

The article data used to support the findings of this study are included within the article.

\section{Conflicts of Interest}

The authors declare that there are no conflicts of interest regarding the publication of this paper.

\section{Acknowledgments}

This work was supported by the National Natural Science Foundation of China (Grant no. 11502229), the Natural Science Foundation of the Jiangsu Higher Education Institutions of China (Grant no. 18KJB440002), the Science and Technology Project of Housing and Construction in Jiangsu Province (Grant no. 2017ZD169), and the Science Foundation of Changzhou Vocational Institute of Engineering (Grant nos. 11130300117011 and 11130800217005).

\section{References}

[1] G. Y. Li and W. F. Zhou, "Impact of karst water on coal mining in North China," Environmental Geology, vol. 49, no. 3, pp. 449-457, 2006.

[2] K. Q. He, G. M. Yu, and Y. R. Lu, "Palaeo-karst collapse pillars in northern China and their damage to the geological environments," Environmental Geology, vol. 58, no. 5, pp. 10291040, 2009.

[3] D. Ma and H. B. Bai, "Groundwater inflow prediction model of karst collapse pillar: a case study for mining-induced groundwater inrush risk," Natural Hazards, vol. 76, no. 2, pp. 1319-1344, 2015.

[4] H. B. Bai, D. Ma, and Z. Q. Chen, "Mechanical behavior of ground water seepage in karst collapse pillars," Engineering Geology, vol. 164, pp. 101-106, 2013.

[5] G. M. Troitzky, Sinkhole Danger-Engineering Problem of Covered Karst, Applied Karst Geology, Balkema, Rotterdam, Netherlands, 1993.

[6] K. Q. He, S. Q. Zhang, F. Wang, and W. Du, "The karst collapses induced by environmental changes of the groundwater and their distribution rules in China," Environmental Earth Science, vol. 61, no. 5, pp. 1075-1084, 2010.

[7] S. X. Yin, S. X. Wang, and Q. Wu, "Water inrush patterns and theoretic criteria of karstic collapse columns," Chinese Journal of Rock Mechanics and Engineering, vol. 23, no. 6, pp. 964968, 2004.

[8] Q. Wu, H. Xu, and W. Pang, "GIS and ANN coupling model: an innovative approach to evaluate vulnerability of karst water inrush in coalmines of north China," Environmental Geology, vol. 54, no. 5, pp. 937-943, 2008.

[9] W. C. Zhu and C. H. Wei, "Numerical simulation on mininginduced water inrushes related to geologic structures using a damage-based hydromechanical model," Environmental Earth Science, vol. 62, no. 1, pp. 43-54, 2011.

[10] B. H. Yao, H. B. Bai, J. P. Wei, D. K. Wang, D. Ma, and Z. Q. Chen, "Numerical study on seepage property of karst collapse columns under particle migration," CMES-Computer Modeling in Engineering and Sciences, vol. 91, no. 2, pp. 81100, 2013.

[11] Y. Xiang, "The mechanics model on flooding process of collapse pillar," Coal Geology Exploration, vol. 21, no. 5, pp. 36-39, 1993.

[12] Q. Wu, L. T. Xing, C. H. Ye, and Y. Z. Liu, "The influence of coal mining on the large karst springs in North China," Environmental Earth Science, vol. 64, no. 6, pp. 1513-1523, 2011.

[13] D. Ma, H. B. Bai, and Y. M. Wang, "Mechanical behavior of a coal seam penetrated by a karst collapse pillar: mininginduced groundwater inrush risk," Natural Hazards, vol. 75, no. 3, pp. 2137-2151, 2015.

[14] Y. S. Zhang, Y. X. Qu, G. L. Liu, and P. J. Lu, "Some problems of karstic collapse pillars in North-China-type coalfields," Journal of Engineering Geology, vol. 8, no. 1, pp. 35-39, 2000.

[15] W. Yang, Z. Zhou, and Z. Li, "Analysis of the filling characteristics of karstic collapse pillars and its reactivationinduced water conducting," Carsologica Sinica, vol. 20, no. 4, pp. 279-283, 2001.

[16] X. X. Miao, S. C. Li, Z. Q. Chen, and W. Q. Liu, "Experimental study of seepage properties of broken sandstone under different porosities," Transport in Porous Media, vol. 86, no. 3, pp. 805-814, 2011

[17] D. Ma, X. X. Miao, G. H. Jiang, H. B. Bai, and Z. Q. Chen, “An experimental investigation of permeability measurement of 
water flow in crushed rocks," Transport in Porous Media, vol. 105, no. 3, pp. 571-595, 2014.

[18] M. Li, J. X. Zhang, and R. Gao, "Compression characteristics of solid wastes as backfill materials," Advances in Materials Science and Engineering, vol. 2016, no. 1, Article ID 2496194, 7 pages, 2016.

[19] H. Darcy, Les Fontaines Publiques de la Ville de Dijon: Exposition et Application, V. Dalmont, Ed., Universite de Grenoble, Paris, French, 1856.

[20] A. K. M. B. Alam, M. Niioka, Y. Fujii, D. Fukuda, and J. Kodama, "Effects of confining pressure on the permeability of three rock types under compression," International Journal of Rock Mechanics and Mining Science, vol. 65, pp. 49-61, 2014

[21] D. Ma, H. B. Bai, Z. Q. Chen, and H. Pu, "Effect of particle mixture on seepage properties of crushed mudstones," Transport in Porous Media, vol. 108, no. 2, pp. 257-277, 2015. 


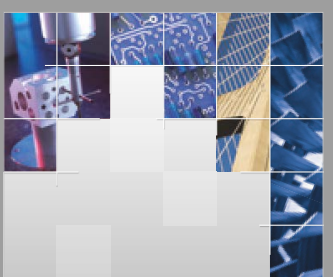

\section{Enfincering}
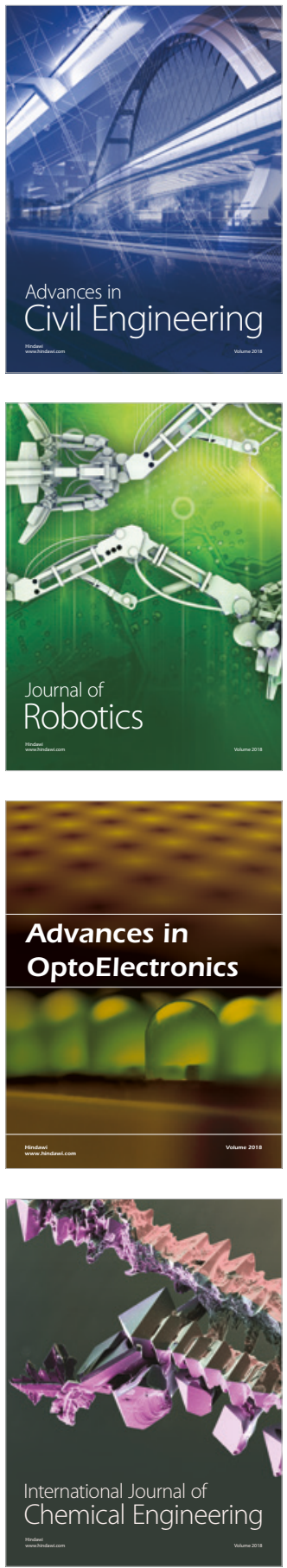

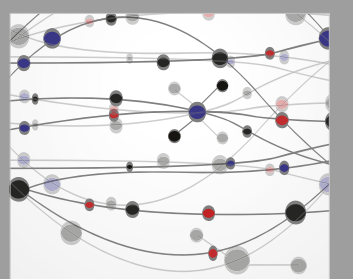

\section{Rotating \\ Machinery}

The Scientific World Journal

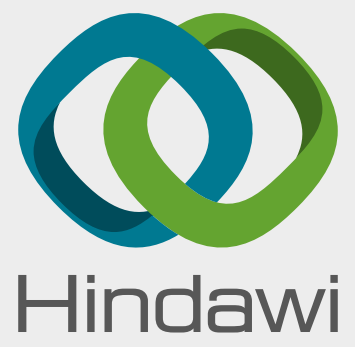

Submit your manuscripts at

www.hindawi.com
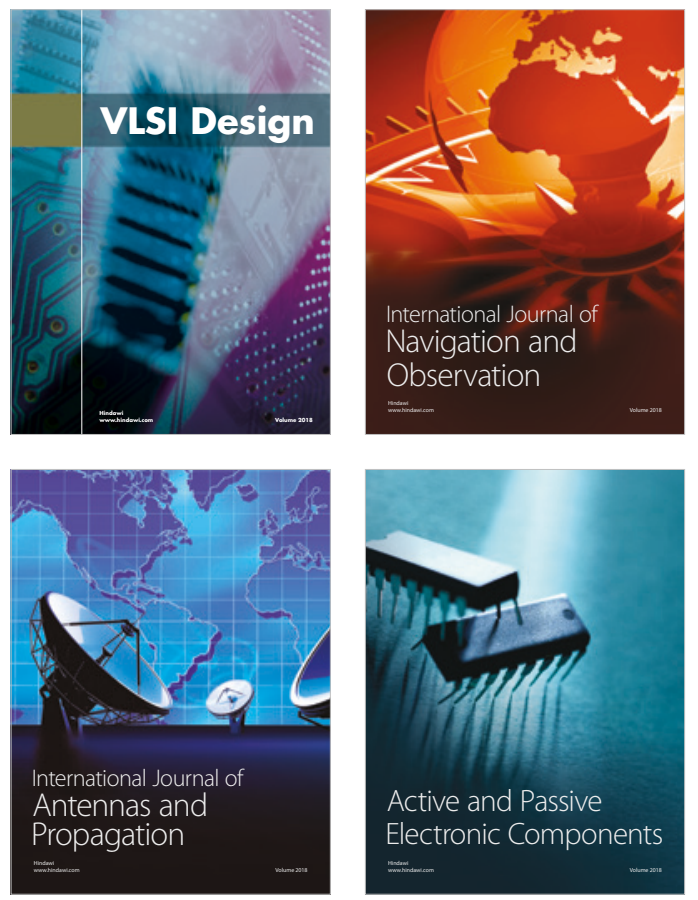
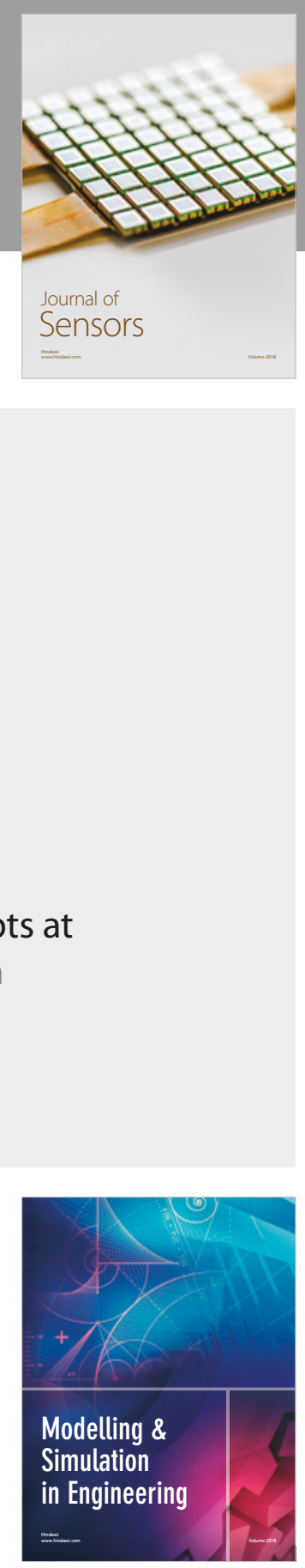

\section{Advances \\ Multimedia}
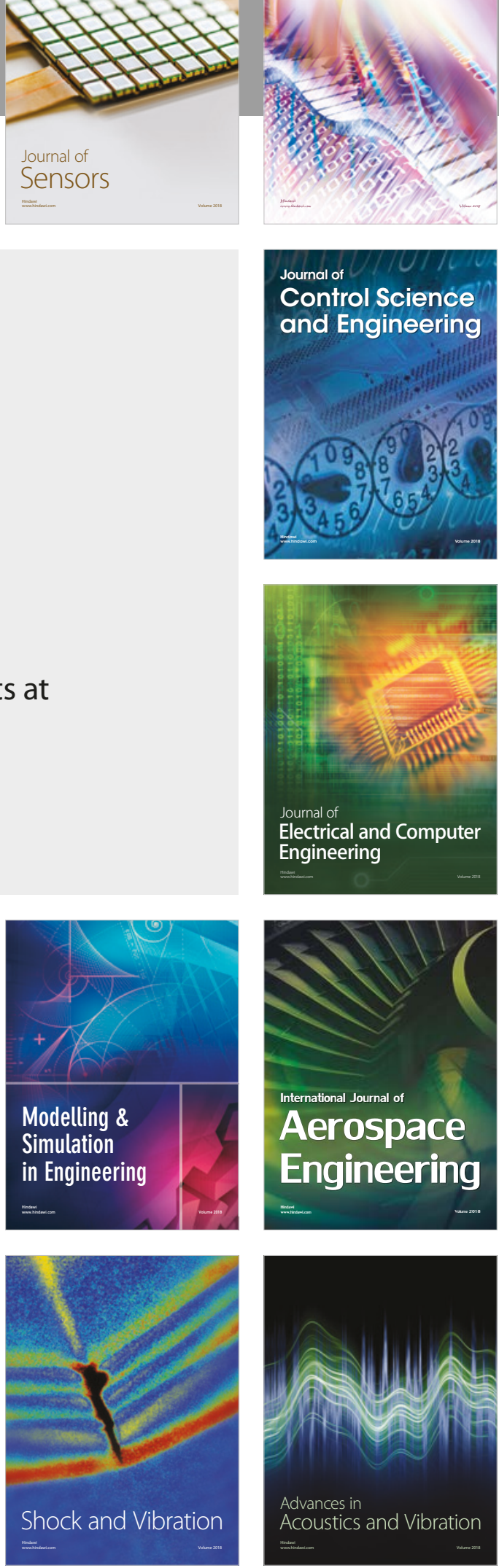